\title{
Online Learning for Primary Level / Madrasah with Online Applications in MIN 2 Serdang Bedagai
}

\author{
Suyanto $^{1 *}$, Nurul Maulida Surbakti ${ }^{1}$, Syahriol Sitorus ${ }^{1}$, Rosman Siregar $^{1}$, Zahedi $^{1}$ \\ ${ }^{1}$ Department of Mathematics, Faculty of Mathematics and Science, Universitas Sumatera \\ Utara, Medan, Indonesia \\ *Email: suyanto@usu.ac.id
}

\begin{abstract}
The online learning system is still having problems. As a result of the observations of the USU team, several obstacles were felt not only by the teachers at MIN 2 Serdang Bedagai but also by students and parents. The problems that occur are quite diverse. Starting from limited signal, limited devices suitable for online learning, to the lack of technological knowledge of teachers and students on online applications that support the teaching and learning process. There are various online applications available today, such as Google Classroom, Zoom, Google Meet, Youtube, and others. These various online applications play an important role in helping students and teachers in the distance learning process. The USU team conducted training using the online application Google Classroom and Zoom. Google Classroom and Zoom were chosen because they are easier for the teacher to implement, besides that the two online applications facilitate coordination and communication between teachers and students, so that the material being taught can be discussed more easily, more freely and can be updated more quickly. In this community service, Online Learning training was conducted for the Elementary School / Madrasah Ibtidaiyah Level with Various Online Applications at MIN 2 Serdang Bedagai. This community service has reached the implementation stage of training which begins with the initial survey stage, provision of training modules and also training. The next stage is monitoring and evaluation and feedback.
\end{abstract}

\section{Keywords: Online Apps, Google Classroom, Online Learning, Zoom}

\begin{abstract}
Abstrak
Sistem pembelajaran secara daring masih menemui kendala. Sebagai hasil amatan tim USU bahwa beberapa kendala tidak hanya dirasakan pihak guru di MIN 2 Serdang Bedagai tetapi juga dikeluhkan oleh siswa dan para orang tua. Permasalahan yang terjadi cukup beragam. Mulai dari keterbatasan sinyal, keterbatasan perangkat yang layak digunakan untuk pembelajaran daring, hingga minimnya pengetahuan teknologi guru dan siswa terhadap aplikasi daring yang mendukung proses KBM. Terdapat berbagai aplikasi daring yang tersedia pada masa sekarang ini, seperti Google Classroom, Zoom, Google Meet, Youtube, dan lain-lain. Berbagai Aplikasi Daring tersebut berperan penting membantu siswa dan guru dalam proses pembelajaran pembelajaran jarak jauh. Tim USU melakukan pelatihan menggunakan aplikasi daring Google Classroom dan Zoom. Google Classroom dan Zoom dipilih karena lebih mudah untuk diterapkan oleh Guru, selain itu kedua aplikasi daring tersebut memudahkan koordinasi dan komunikasi antara guru dan murid, sehingga materi yang diajarkan dapat didiskusikan dengan lebih mudah, lebih leluasa dan bisa diperbarui lebih cepat. Pada pengabdian kepada masyarakat ini, dilakukan pelatihan Pembelajaran Daring untuk Tingkat Sekolah Dasar/Madrasah Ibtidaiyah dengan Berbagai Aplikasi Daring di MIN 2 Serdang Bedagai. Pengabdian kepada masyarakat ini telah sampai pada tahap pelaksanaan pelatihan yang diawali dengan tahapan survey awal, penyediaan modul pelatihan dan juga pelatihan. Tahapan selanjutnya adalah monitoring dan evaluasi serta feedback.
\end{abstract}

Kata Kunci: Aplikasi Daring, Google Classroom, Pembelajaran Daring, Zoom 


\section{PENDAHULUAN}

MIN 2 Serdang Bedagai berlokasi di Jl. Salman Al Farisi. Kecamatan Serbajadi. Kabupaten Serdang Bedagai, Provinsi Sumatera Utara dengan total jumlah guru sekitar 25 orang. Akibat adanya pandemik COVID-19 menyebabkan adanya pembatasan interaksi sehingga Kementerian Pendidikan di Indonesia mengeluarkan kebijakan yaitu dengan meliburkan sekolah dan mengganti proses Kegiatan Belajar Mengajar (KBM) dengan menggunakan sistem dalam jaringan (daring).

Sebagai hasil observasi di lapangan dan atas dasar diskusi yang dibangun dua arah yaitu antara mitra-tim abdimas USU diperoleh informasi bahwa Sistem pembelajaran secara daring masih menemui banyak kendala. Beberapa kendala tidak hanya dirasakan pihak guru di MIN 2 Serdang Bedagai tetapi juga dikeluhkan oleh siswa dan para orang tua. Permasalahan yang terjadi cukup beragam. Mulai dari keterbatasan sinyal, keterbatasan perangkat yang layak digunakan untuk pembelajaran daring, hingga minimnya pengetahuan teknologi guru dan siswa terhadap aplikasi daring yang mendukung proses KBM. Dalam upaya membantu guru dalam menggunakan aplikasi daring sebagai media pembelajaran, MIN 2 Serdang Bedagai bekerjasa sama dengan tim pengabdian masyarakat dari Universitas Sumatera Utara (abdimas USU) untuk Tahun Akademik 2020.

Pembelajaran Online adalah pembelajaran yang bertujuan untuk mempermudah kedua belah pihak (guru dan siswa) dalam penyampaian materi ajar secara daring. Pembelajaran dilakukan dengan mengakses materi yang telah diunggah oleh guru ke web menggunakan internet atau intraner LAN/WAN. (Hasibuan, Simarmata, dan Sudirman, 2019).

\section{METODE PELAKSANAAN}

Setelah diskusi dengan mitra tentang aplikasi daring yang akan digunakan oleh guru dan siswa, tim abdimas USU memilih aplikasi daring berupa Google Classroom dan Zoom. Tim abdimas USU memberikan pelatihan tentang sistem pembelajaran daring, menanamkan pola pikir tentang cara baru belajar. Kemudian melatih para guru merancang, mengorganisir, serta mengendalikan aktivitas dan materi belajar yang interaktif untuk mencapai tujuan belajar. Kemudian, memperkenalkan beberapa aplikasi daring yang tersedia serta penggunaan aplikasi-aplikasi tersebut kepada guru agar proses KBM berlangsung efektif dan efisien.

Pelaksanaan Pengabdian ini dilakukan dalam dua tahapan besar, yaitu:

1. Pelatihan penyiapan rencana proses pembelajaran dan pembuatan bahan ajar secara daring.

2. Pelatihan kegiatan belajar mengajar secara Daring.

Adapun tahapan pelaksanaan kegiatan disesuaikan dengan masalah mitra sebagai berikut:

1. Memberikan motivasi bahwa guru harus mampu melaksanakan pembelajaran daring.

2. Menanamkan rasa percaya diri bahwa setiap guru pasti bisa menyiapkan bahan ajar merancang, mengorganisir, serta mengendalikan aktivitas dan materi belajar yang interaktif untuk mencapai tujuan belajar.

3. Memperkenalkan dan memberi pendampingan penggunaan aplikasi daring Google Classroom dan Zoom.

4. Mengajarkan bagaimana merancang, mengorganisir, serta mengendalikan aktivitas dan materi belajar menggunakan aplikasi daring Google Classroom dan Zoom.

5. Memberikan kesempatan untuk diskusi dalam jarak jauh dengan para peserta

6. Mengevaluasi hasil yang telah dibuat oleh mitra dan memberikan umpan balik (feed back).

\section{HASIL DAN PEMBAHASAN}

Berikut adalah beberapa kegiatan yang sudah dilakukan dalam pengabdian kepada masyarakat yang dilakukan di MIN 2 Serdang Bedagai, 
1. Pembuatan video panduan dasar menginstall dan menggunakan Aplikasi daring Google Classroom dan Zoom untuk keberlangsungan proses Kegiatan Belajar Mengajar (KBM) dengan menggunakan sistem dalam jaringan (daring).

2. Persiapan sebelum pelatihan.

3. Pelatihan.

\subsection{Pembuatan Video Panduan Dasar Penggunaan Aplikasi Daring Google Classroom dan Zoom Meeting, Slide Panduan Dasar Cara mengakses dan Slide Panduan Dasar Google Classroom dan Zoom Meeting}

Ada tiga video berdurasi 7 sd 10 menit terkait panduan dasar Google Classroom dan Zoom Meeting yang sudah dibuat. Video pertama memuat penjelasan tentang cara menginstall Google Classroom dan Zoom Meeting. Video kedua memuat penjelasan singkat terkait jendela, menu dan tools yang ada di aplikasi daring Google Classroom dan Zoom Meeting. Video terakhir berisi beberapa contoh cara membuat grafik dan gambar menggunakan Google Classroom dan Zoom Meeting.

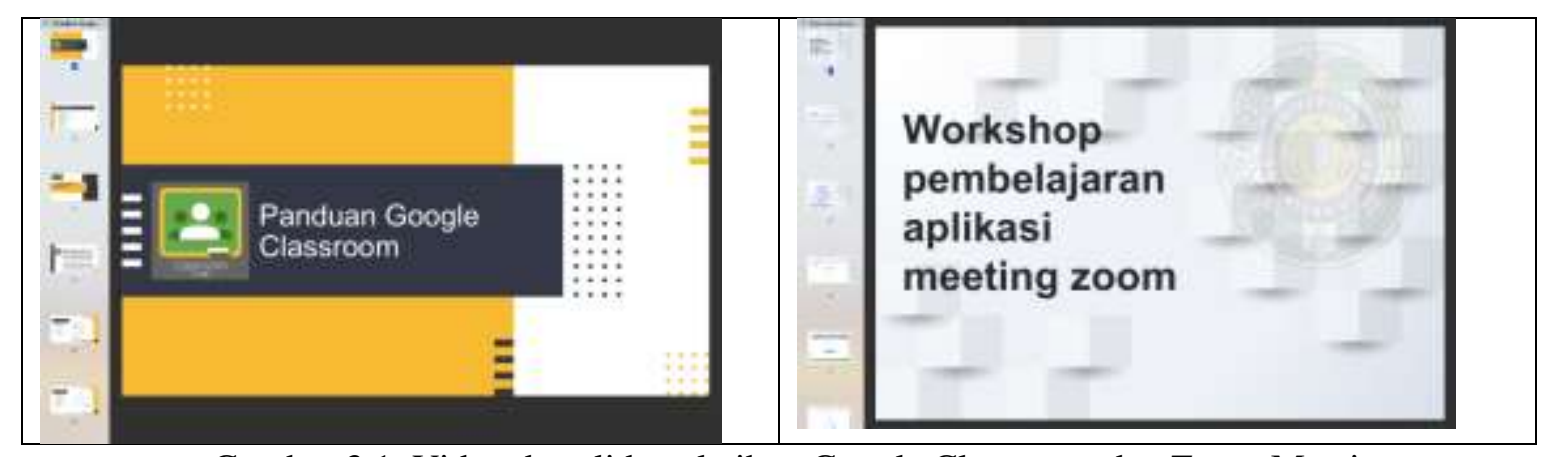

Gambar 3.1. Video dan slide pelatihan Google Classroom dan Zoom Meeting

\section{Persiapan Pelatihan}

Kegiatan pengabdian ini dilakukan oleh tim pengabdian kepada masyarakat pada hari Sabtu, 17 Oktober 2020. Seluruh tim Abdimas hadir di lokasi pengabdian, tim berangkat dari Medan menggunakan jalur darat di hari sabtu pagi.

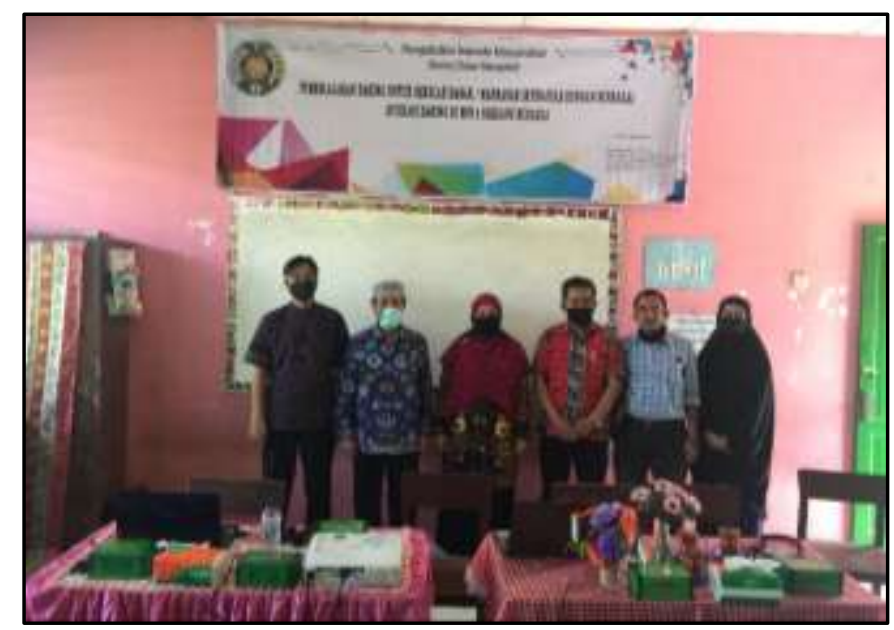

Gambar 3.2. Tim Abdimasi dan Kepala Sekolah MIN 2 Serdang Bedagai 
Kegiatan dilakukan di kelas I-A MIN 2 Serdang Bedagai. Kegiatan dilakukan pada satu ruangan dengan jumlah peserta 25 orang. Kegiatan ini dilakukan pada masa pandemi Covid-19 sehingga kegiatan dilakukan dengan mematuhi protokol kesehatan. Tim dan mitra (para guru) menggunakan masker.
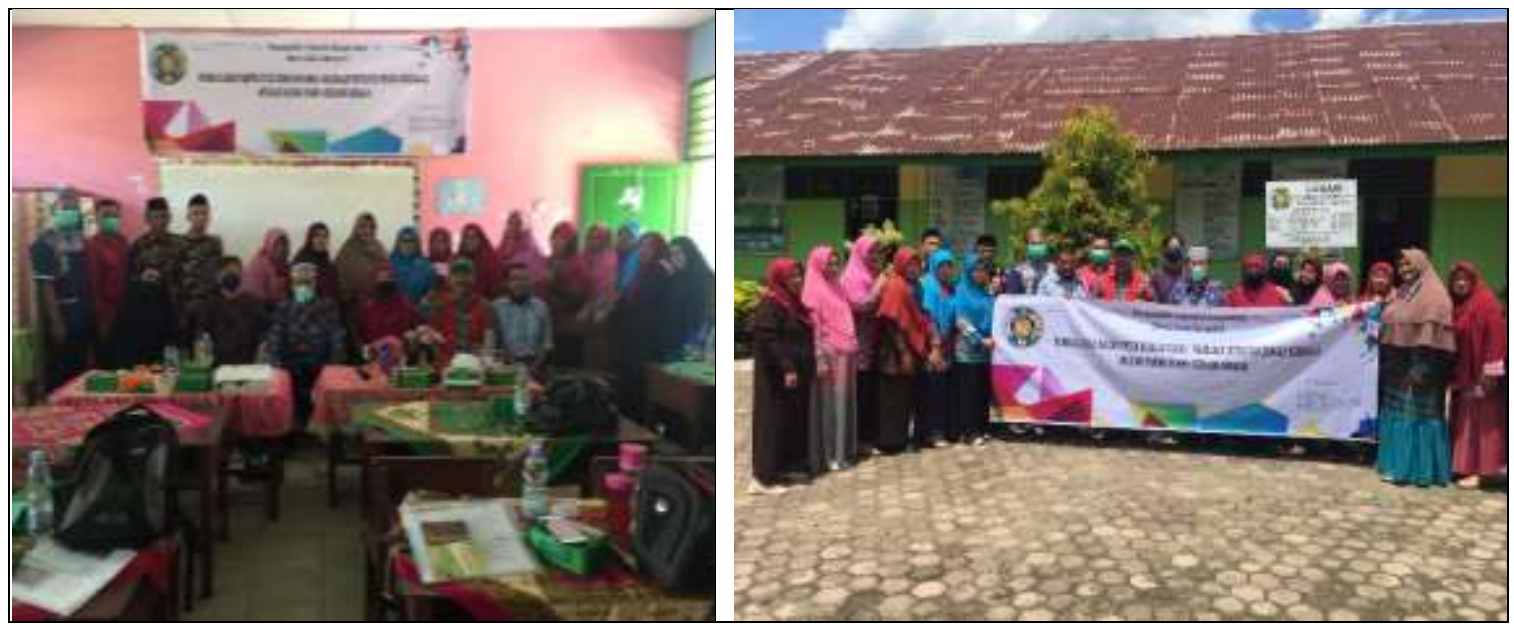

Gambar 3.3. Lokasi Pengabdian di MIN 2 Serdang Bedagai (kanan) dan Ruang Pelatihan (kiri)

2. Pelatihan dan Penggunaan Aplikasi Daring Google Classroom dan Zoom Meeting. Pelatihan dan sosialisasi dilakukan Sabtu, 17 Oktober 2020 di kelas I-A MIN 2 Serdang Bedagai. Pelatihan dibuka oleh Pak Dr. Suyanto, M.Kom selaku ketua pelaksana kemudian diikuti kata sambutan oleh Kepala Sekolah MIN 2 Serdang Bedagai Ibu Rosmida Sihotang, S.Pd.

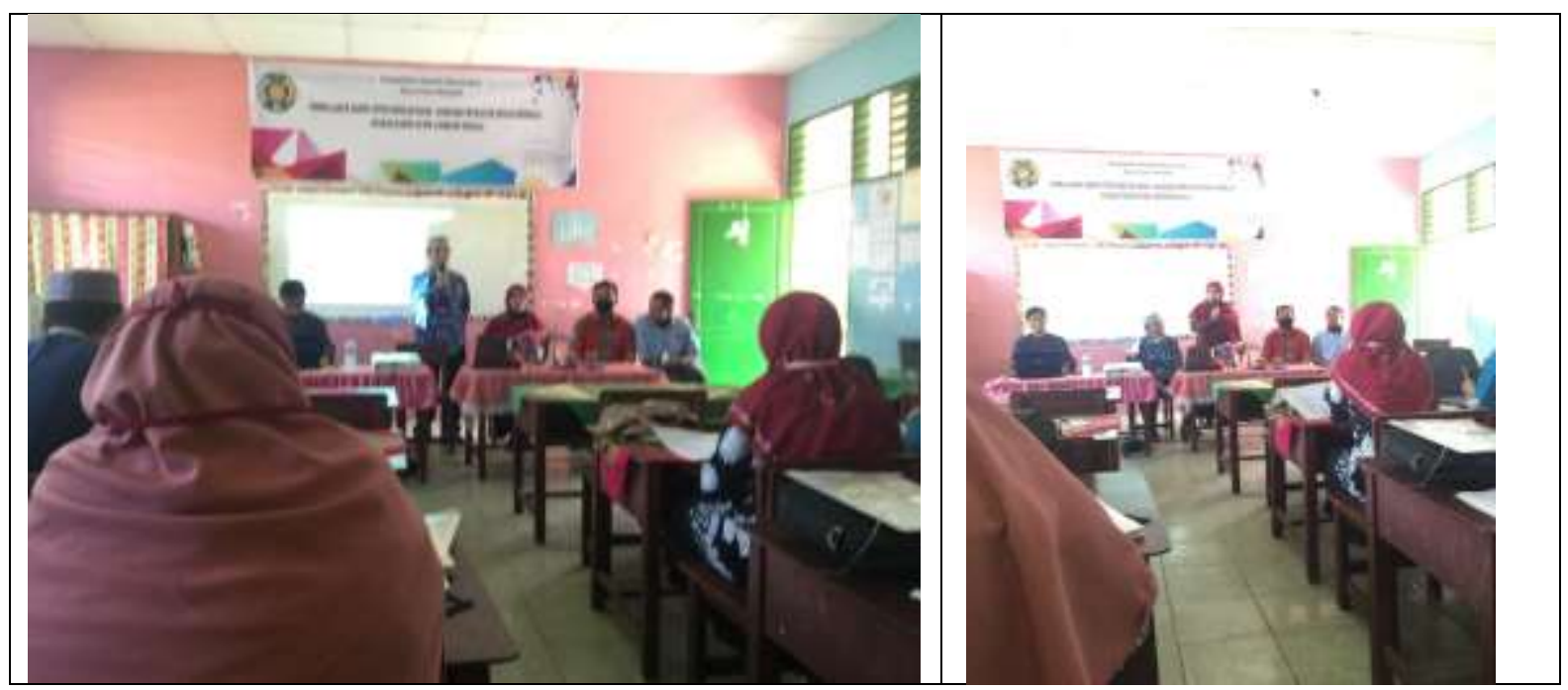

Gambar 3.4. Pembukaan oleh Pak Dr. Suyanto, M.Kom (kiri) dan Kata Sambutan oleh Kepala Sekolah MIN 2 Serdang Bedagai Ibu Rosmida Sihotang, S.Pd. (kanan)

Setelah pembukaan dilakukan, ketua pelaksana memberikan cinderamata berupa Printer Canon $2570 \mathrm{P} / \mathrm{S} / \mathrm{C} \mathrm{R}$ dan piagam penghargaan yang diterima langsung oleh kepala sekolah MIN 2 Serdang Bedagai sebagai kenang-kenang atas pengabdian yang dilakukan. 


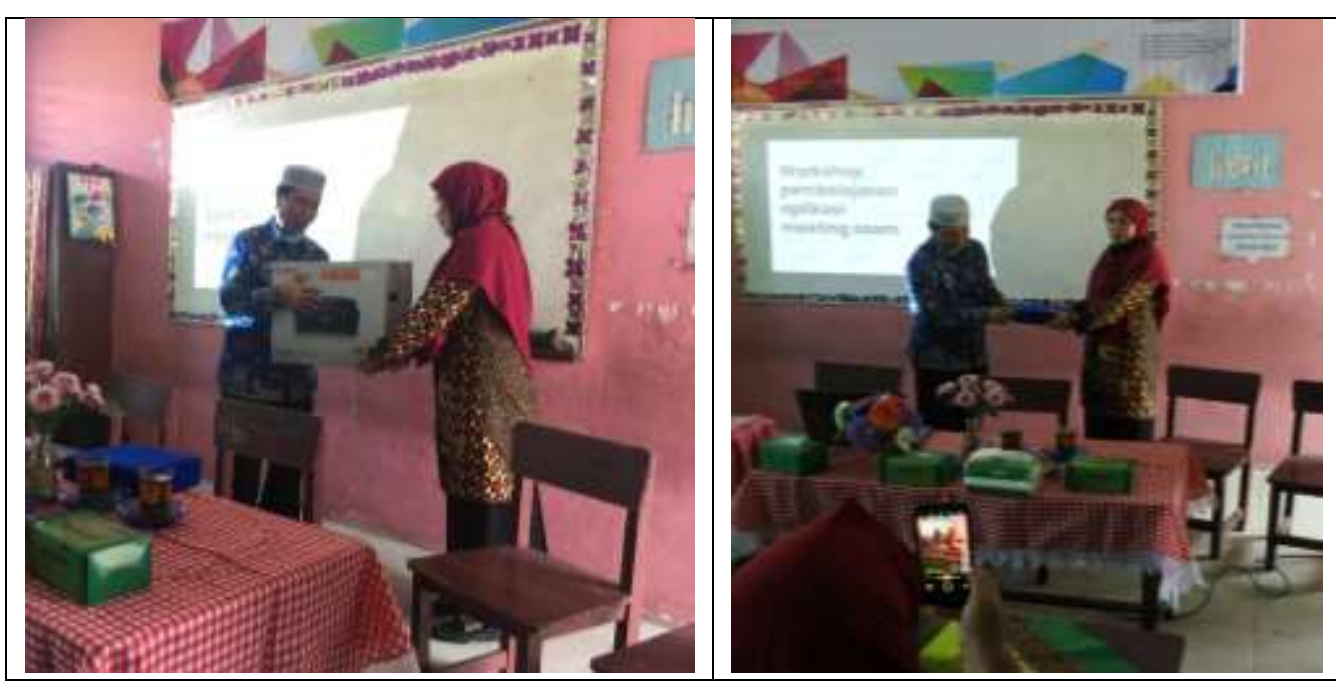

Gambar 3.5. Pemberian Cinderamata (kiri) dan Piagam Penghargaan (kanan) oleh ketua pelaksana kepada Kepala Sekolah MIN 2 Serdang Bedagai

Peserta selanjutnya diarahkan untuk mengikuti pelatihan. Pelatihan dibuka oleh Pak Suyanto yang menyampaikan secara singkat jenis-jenis pelatihan yang akan diberikan. Ada dua jenis pelatihan yang diberikan yaitu pelatihan terkait Google Classroom dan Zoom Meeting untuk menyiapkan bahan ajar merancang, mengorganisir, serta mengendalikan aktivitas dan materi belajar yang interaktif untuk mencapai tujuan belajar.

Pelatihan terkait Google Classroom diberikan oleh Nurul Maulida Surbakti melalui presentasi dan praktik langsung. Terakhir Pelatihan Google Classroom dan Zoom juga diberikan oleh Syahriol Sitorus.
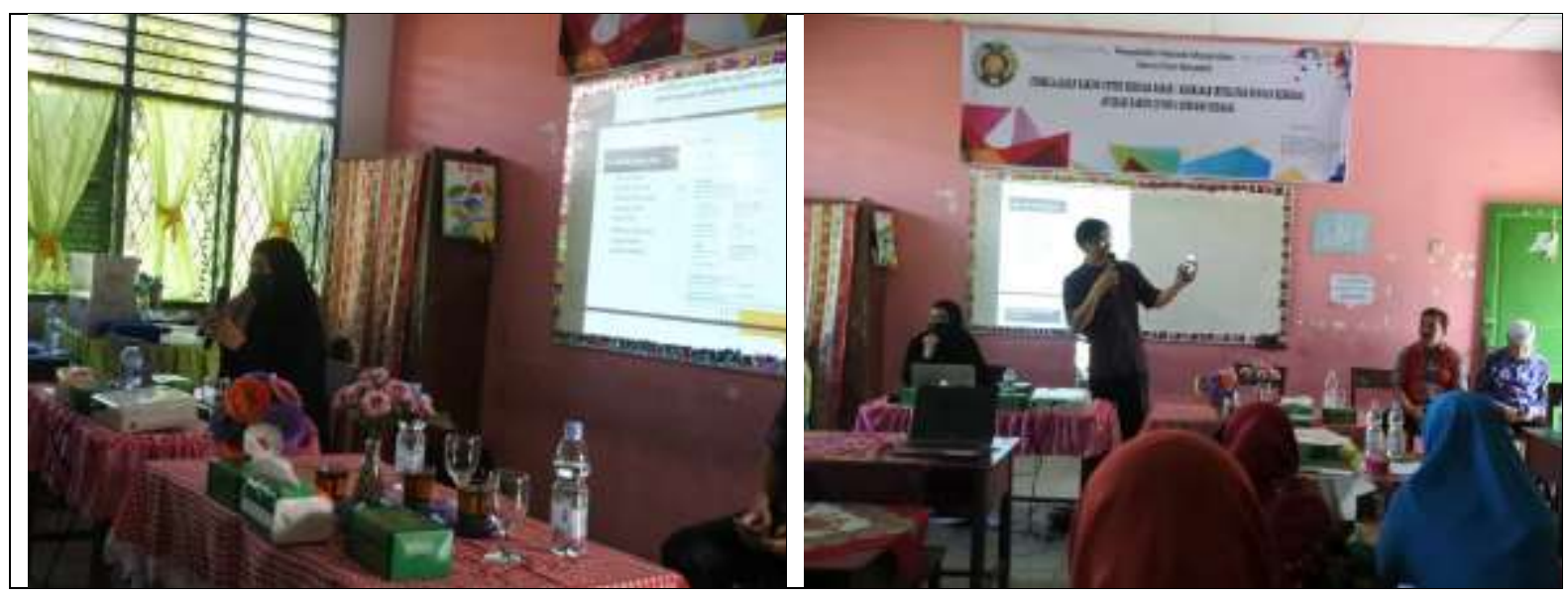

Gambar 3.6. Pelatihan Google Classroom oleh Bu Nurul Maulida Surbakti (kiri) Pelatihan Google Classroom dan Zoom Meeting oleh pak Syahriol Sitorus (kanan)

\section{KESIMPULAN}

Adapun kesimpulan yang diperoleh dari kegiatan pengabdian masyarakat di MIN 2 Serdang Bedagai yaitu,

1. Kegiatan pengabdian masyarakat yang telah dilakukan mendapatkan respon yang sangat baik dari Kepala Sekolah MIN 2 Serdang Bedagai dan Guru-guru di MIN 2 Serdang Bedagai. 
2. Terjadi peningkatan kemampuan guru khususnya kemampuan akan penggunaan aplikasi daring Google Classroom dan Zoom Meeting sebagai objek dari pengabdian masyarakat ini.

3. Guru memiliki kemampuan menggunakan aplikasi daring Google Classroom dan Zoom Meeting untuk menyiapkan bahan ajar merancang, mengorganisir, serta mengendalikan aktivitas dan materi belajar yang interaktif untuk mencapai tujuan belajar.

\section{UCAPAN TERIMAKASIH}

Terimakasih kepada Rektor USU dan LPPM USU yang telah memberikan dana pengabdian tahun 2020 Skema Dosen Wajib Mengabdi.

\section{DAFTAR PUSTAKA}

HomeEdition. 2005, Macromedia flash Profesional 8 help, Macromedia Inc

Juhaeri. 2009. Pengantar Multimedia untuk Media Pembelajaran bagian I, Ilmu Komputer.

Retno, Margono dan Bambang Eka Purnama. ISSN 1979 - 9330. Study of Interaktif Recognition Letter and Number for Children with Computer Multimedia. Indonesian jurnal on Computer Science - Speed (IJCSS) 4 Vol. 3 Nomor 1 Agustus 2008

Script Island. 2008. Panduan Mudah Membuat Animasi. Jakarta: Media Kita.

Tulus, Sawaluddin, T.J. Marpaung, dan M.R. Syahputra. 2018. Making Learning Teaching Materials in School Based on Information and Communication Technology. Abdimas Talenta. Vol. 3 No. 2 pp. 202-2016 